\title{
Diabetes Mellitus: Glucose Control
}

Dr. Noel P Somasundaram, Prof. Chandrika N Wijeyaratne, Prof. Shamya De Silva, Prof. Sisira Siribaddana, Prof. Upali Illangasekera, Dr. Henry Rajaratnam, Dr. Prasad Katulanda, Dr. Uditha Bulugahapitiya, Dr. Sajith Siyambalapitiya, Dr. Charles Antonypillai, Dr. Manilka Sumanatilleke, Dr. Gaya Katulanda, Dr. Priyankara Jayawardena, Dr. N. Sudheera Kalupahana, Dr. Renuka Jayatissa, Dr. Chaminda Garusinghe, Dr. Dimuthu Muthukuda, Dr. Niranjala Meegoda Widanege, Dr. Muditha Weerakkody, Dr. Sivatharshya Pathmanathan, Dr. Sachith Abhayaratna, Dr. Shyaminda Kahandawa, Dr. Kavinga Gunawardane, Dr. Nayananjani Karunasena, Dr. M. Aravindhan, Dr. W. S. T. Swarnasri, Dr. Navoda Atapattu.

Sri Lanka Journal of Diabetes, Endocrinology and Metabolism 2013; 3: 45-57

\begin{tabular}{|c|c|}
\hline \multicolumn{2}{|l|}{ Abbreviations } \\
\hline ACEI & $\begin{array}{l}\text { Angiotensin-converting enzyme } \\
\text { inhibitor }\end{array}$ \\
\hline $\mathrm{ANC}$ & Antenatal care \\
\hline $\mathrm{ARB}$ & Angio sin II receptor blocker \\
\hline BIDS & Basal insulin day time sulfonylurea regimen \\
\hline CKD & Chronic kidney disease \\
\hline CVD & Cardiovascular disease \\
\hline DCCT & Diabetes control and complications trial \\
\hline DPP-4 inhibitor & Dipeptidyl peptidase-4 inhibitors \\
\hline eGFR & Estimated glomerular filtration rate \\
\hline FPG & Fasting plasma glucose \\
\hline GI & Gastrointestinal \\
\hline GLP-1 RA & Glucagon-like peptide-1 receptor agonist \\
\hline $\mathrm{HbA1C}$ & Glycosylated haemoglobin \\
\hline IADPSG & $\begin{array}{l}\text { International Association of Diabetes and } \\
\text { Pregnancy Study Group }\end{array}$ \\
\hline ICU & Intensive care unit \\
\hline MODY & Maturity onset diabetes of the young \\
\hline NGSP & $\begin{array}{l}\text { National Glycohaemoglobin } \\
\text { Standardization Program }\end{array}$ \\
\hline $\mathrm{NPH}$ & $\begin{array}{l}\text { Neutral protamine hagedorn (isophane } \\
\text { insulin) }\end{array}$ \\
\hline OGTT & Oral glucose tolerance test \\
\hline PPG & Postprandial glucose \\
\hline SMBG & Self monitoring of blood glucose \\
\hline T1DM & Type 1 diabetes mellitus \\
\hline T2DM & Type 2 diabetes mellitus \\
\hline TDD & Total daily dose \\
\hline TZD & Thiazolidinediones \\
\hline
\end{tabular}

\section{Introduction}

Around 1.5 million Sri Lankan adults suffer from diabetes and the number is expected to rise up to 2.1 million by the year 2030. Diabetes mellitus is the leading cause of myocardial infarction, stroke, chronic kidney disease, blindness in adults and amputations. Prevention of these complications requires evidence based multiple risk factor approach and patient centred self management approach with multidisciplinary support. Early intensive glycaemic control decreases microvascular complications and improves cardiovascular outcomes.

\section{Glycaemic control - glycaemic targets}

\begin{tabular}{ll}
\hline HbA1C & $\leq 7.0 \%$ \\
\hline $\begin{array}{l}\text { Pre-prandial capillary } \\
\text { plasma glucose }\end{array}$ & $\begin{array}{l}70-130 \mathrm{mg} / \mathrm{dL} \\
(3.9-7.2 \mathrm{mmol} / \mathrm{L})\end{array}$ \\
\hline $\begin{array}{l}\text { Peak post-prandial } \\
\text { capillary plasma glucose }\end{array}$ & $<180 \mathrm{mg} / \mathrm{dL}$ \\
\end{tabular}

- More stringent $\mathrm{HbA} 1 \mathrm{C}$ targets, i.e.: 6.0-6.5\% might be considered in selected patients (with short disease duration, long life expectancy, no significant CVD and also before conception in women) if this can be achieved without significant hypoglycaemia or other adverse effects of treatment.

- Less stringent HbA1C targets, i.e.: 7.5-8.0\% is appropriate for patients with severe hypoglycaemia, limited life expectancy, advanced complications and extensive co-morbid conditions.

Disclaimer: Clinical Practice Guidelines are developed to be of assistance to health care professionals by providing guidance and recommendations for particular areas of practice. The guidelines should not be considered inclusive of all proper approaches or methods, or exclusive of others. The guidelines cannot guarantee any specific outcome, nor do they establish a standard of care. The guidelines are not intended to dictate the treatment of a particular patient. Treatment decisions must be made based on the independent judgment of health care providers and each patient's individual circumstances. The Endocrine Society of Sri Lanka makes no warranty, express or implied, regarding the guidelines and specifically excludes any warranties of merchantability and fitness for a particular use or purpose. The Society shall not be liable for direct, indirect, special, incidental, or consequential damages related to the use of the information contained herein. Endocrine Society of Sri Lanka thanks Novo Nordisk for funding the development of these.

(C)Endocrine Society of Sri Lanka, 2013 


\section{Monitoring of glycaemic control}

Ideally a combination of $\mathrm{HbA} 1 \mathrm{C}$ and self monitoring with capillary glucose will give optimal results.

\section{Self monitoring of blood glucose (SMBG)}

- Refers to monitoring by the patient using a glucometer

- Recommended for patients on multiple insulin doses or insulin pump therapy

- The practice of monitoring glucose control with a monthly FPG is suboptimal and has many limitations.

\section{HbA1C}

HbA1C should be measured by a NGSP certified method (standardised to the DCCT reference)

\section{Frequency of $\mathrm{HbA1C}$}

- When glycaemic control is stable, A1C test is recommended 6 monthly.

- When glycaemic control is inadequate, A1C test is recommended 3 monthly.

- HbA1C can be used to check the accuracy of SMBG results and the adequacy of testing schedules.

\section{Limitations of $\mathrm{HbA} 1 \mathrm{C}$}

- In patients with haemoglobinopathy or high red cell turnover values may be discordant with clinical status.

- In patients who have high glycaemic variability self monitoring of blood glucose is recommended.

\section{Treatment of Type 2 Diabetes}

\section{Lifestyle modification}

- Interventions targeted at changing the dietary habits, physical activity and cessation of smoking are key elements to the management of diabetes

\section{Medical nutrition therapy}

- Should be individualized and ideally given by a trained health professional

- Weight loss is recommended (at least 5-10\%) for all overweight or obese individuals

- Calorie restricted diet is recommended for weight loss (this may have to be modified based on individual response)

- Routine supplementation with antioxidants and vitamins is not recommended

- Alcohol is best avoided. (If taken it should be less than two units per day for men and less than one unit per day for women).

o One unit of alcohol is defined as $8 \mathrm{~g}(10 \mathrm{ml})$ of pure alcohol

\section{Physical activity}

- Moderate intensity aerobic physical activity: at least $150 \mathrm{~min} /$ week spread over at least 3 days per week with no more than 2 consecutive days without exercise is recommended (e.g. brisk walk 30 minutes a day 5 days a week). For obese at least 60 minutes a day is recommended.

- Resistance training is recommended at least twice a week.

Contraindications are:

o proliferative diabetic retinopathy (PDR)

o severe non proliferative diabetic retinopathy (NPDR)

o uncontrolled hypertension and severe CVD

- Encourage muscle-strengthening activities that involve all major muscle groups, 2 or more days per week.

- Vigorous exercise should be avoided in the presence of ketosis especially in type 1 diabetes, but not with simple hyperglycaemia.

- Patients with peripheral neuropathy can engage in moderate intensity walking.

- Non-weight bearing exercise is recommended for patients with:

o A foot injury or open ulcer

o Osteoarthritis

- For those at high risk of ischaemic heart disease, cardiac evaluation is recommended before initiating vigorous exercise.

\section{Initiation of pharmacotherapy}

- Metformin is the preferred first-line oral therapy unless contraindicated. It has long-standing evidence base for efficacy, safety and cardiovascular risk protection.

- At diagnosis, monotherapy with metformin along with lifestyle interventions is the preferred choice as most patients cannot achieve recommended targets on lifestyle intervention alone.

- If the FPG >200 mg/dL at diagnosis consider starting with two drugs.

- In the presence of severe hyperglycaemia (FPG $>300$ $\mathrm{mg} / \mathrm{dl}$ ) consider treatment with dual/triple therapy or with insulin.

- Consider insulin therapy if there are severe symptoms or complication

- Early combination therapy is preferred than prolonged monotherapy in achieving glycaemic targets. 
Figure 1. Algorithm for glucose lowering in type 2 diabetes

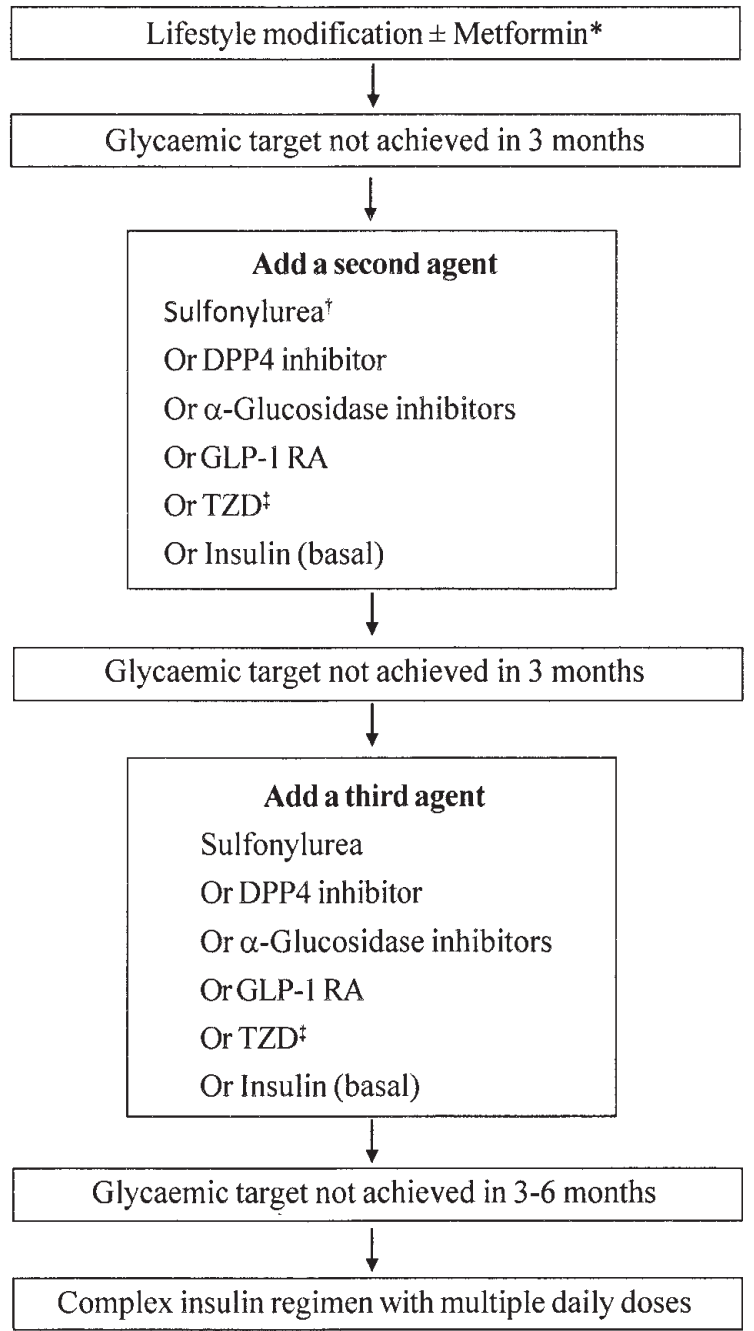

*If metformin is not tolerated or contraindicated: sulfonylureas, DPP4 inhibitor, GLP-1 RA or acarbose can be used as first-line medication. $\uparrow$ Sulfonylureas are the preferred second choice due to cost, and absence of robust data on superiority of other agents.

†TZD (pioglitazone) is not preferred due to safety concerns.

\section{Initiation of insulin therapy}

- Start with basal insulin day time sulfonylurea regimen (BIDS)

o Keep the oral agents and add bedtime basal insulin (isophane or long acting insulin analogues).

o Starting dose is 6-10 units (0.1-0.2 U/kg/day). But higher doses can be used in severe hyperglycaemia (0.3-0.4 U/kg/day).

o Adjust doses by 1-2 U (or 5-10\% increments if on higher doses) once or twice a week until target FPG is achieved.

- Change to split-mixed insulin (pre-mixed insulin) regimen when:

o postprandial glucose is $>180 \mathrm{mg} / \mathrm{dl}$ o HbA1C remains elevated with normal fasting blood sugars with basal insulin

o Basal insulin dose exceeds $0.5-1 \mathrm{U} / \mathrm{kg} /$ day

- Start "basal-bolus" therapy if glucose targets are not easily achieved with split-mixed regimen.

- Total daily insulin requirement is $0.5-1 \mathrm{U} / \mathrm{kg} / \mathrm{day}$ in type 1 diabetes but can be much higher in type 2 diabetes.

- When basal insulin is started metformin is often continued.

- Continuing the secretagogues may minimize initial deterioration of glycaemic control but should be avoided once prandial insulin regimens are employed.

- TZDs should be reduced in dose or stopped to avoid oedema and excessive weight gain. 
Table 1. Non-insulin therapies for type 2 diabetes

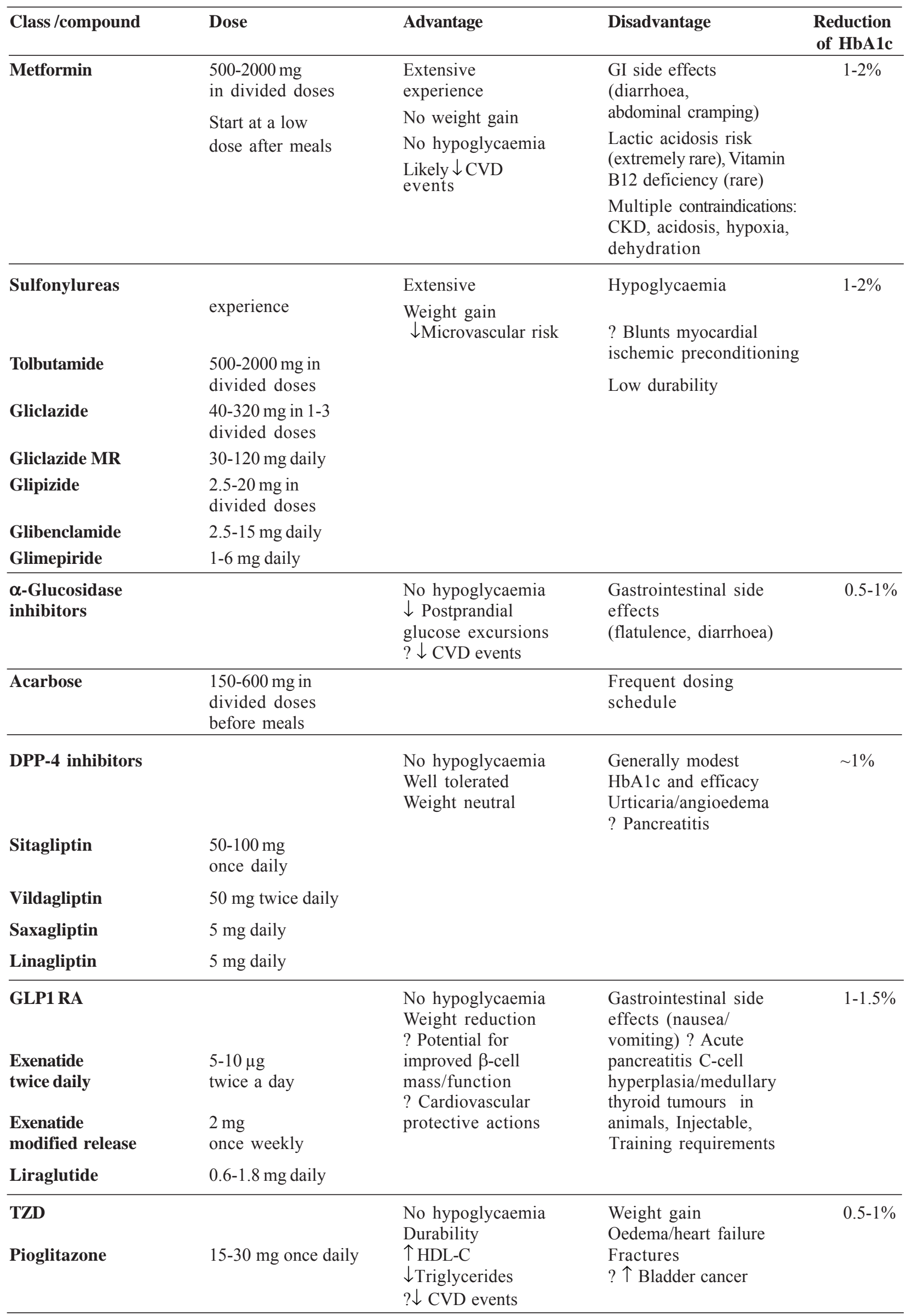




\section{Figure 2. Sequential insulin strategy in type 2 diabetes}

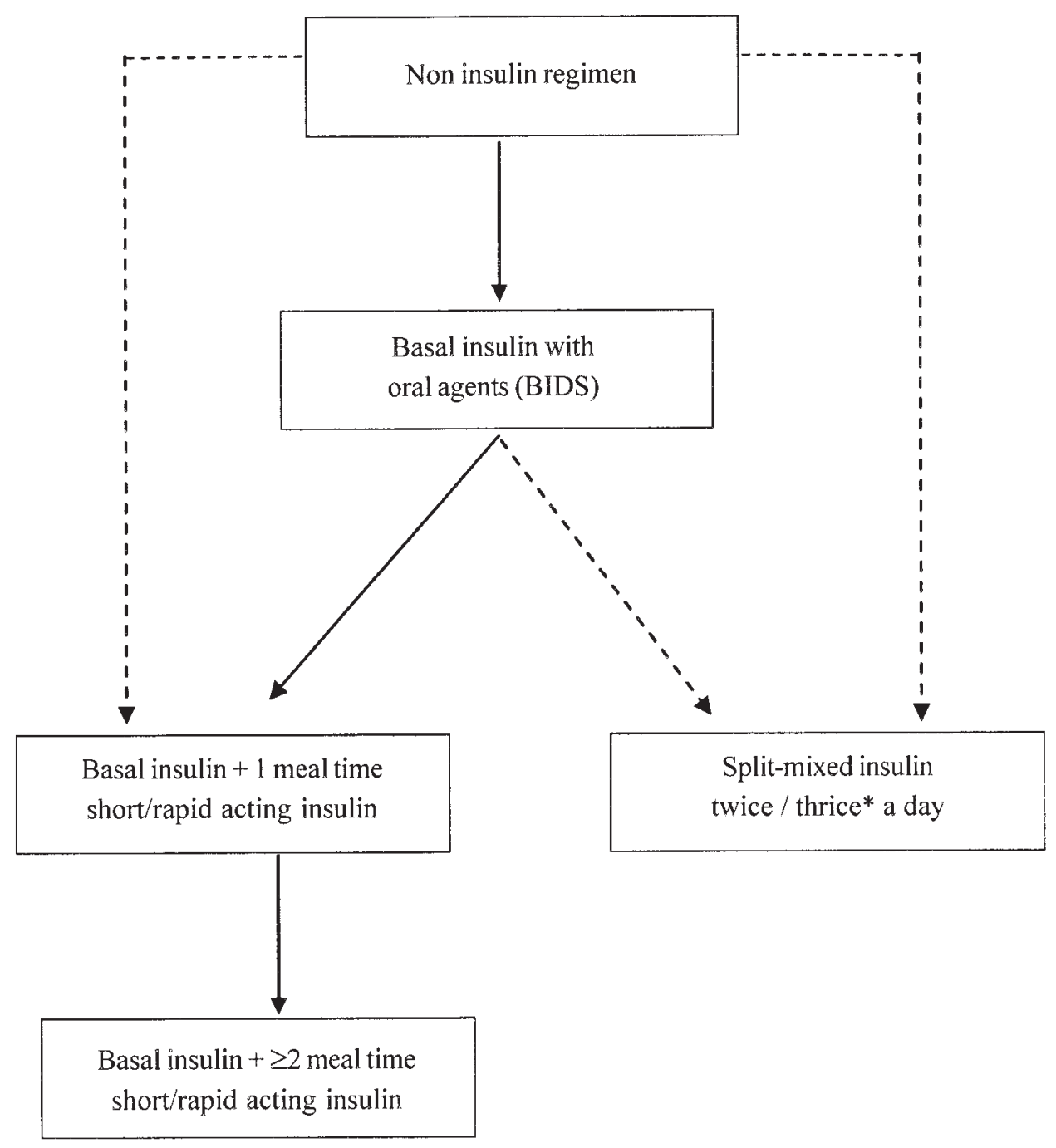

*If analogue insulin is used 


\section{Diabetes in Children}

Type 1 diabetes mellitus (T1DM) is the most common form of diabetes among children. However, the incidence of type 2 diabetes mellitus (T2DM) is increasing among the youth, in parallel with the increasing prevalence of obesity.

\section{Management}

- Children with diabetes should be referred to a specialized centre.

- They should be managed by a diabetes team/ multidisciplinary team (paediatric endocrinologist/ paediatrician, nurse educator, dietician/nutritionist, psychologist, social worker).

- Several aspects have to be addressed in the management of a child with T1DM (e.g. growth, unpredictable dietary and exercise patterns and high risk for hypoglycaemia).

- Education of parents/care givers and teachers is crucial for optimum care of the child.

- Diet - Calculate the energy requirement based on the weight and translate the carbohydrate proportion into portions and distribute throughout the day as 3 main meals and 3 snacks.

\section{- Insulin treatment for type $1 \mathrm{DM}$}

o Dose - 0.5-1 U/kg/day. Dose has to be reduced during the 'honeymoon' phase.

o Regimen - twice daily or basal-bolus regimen.
Careful consideration is essential prior to deciding on the regimen.

- Oral agents may be considered in type 2 diabetes and MODY.

- Glycaemic control - targets are less stringent than for adults. Home blood glucose monitoring is essential for successful glycaemic control.

- Exercise - no restriction in physical activity. A change in the insulin dose or snack may be necessary during the activity.

- Sick day management - insulin should never be stopped. Dose adjustments will be necessary depending on intake of food.

\section{- Hypoglycaemia}

Plasma glucose level below $72 \mathrm{mg} / \mathrm{dL}$ ( $4 \mathrm{mmol} / \mathrm{L}$ ).

Clinical presentations are variable.

\section{Management of hypoglycaemia}

- If conscious: oral glucose/sweetened drink followed by a snack.

- If unconscious or convulsing: Intravenous dextrose or glucagon SC $(30 \mu \mathrm{g} / \mathrm{kg})$.

- At home/school as a first aid measure, apply glucose on the inner surface of child's lips with the finger.

Table 2. Glycaemic targets in children

\begin{tabular}{l|c|c|c|c|c}
\hline \multirow{2}{*}{ Age group } & \multicolumn{2}{|c|}{ Before meals } & \multicolumn{2}{c|}{ Bedtime } & $\begin{array}{c}\text { HbA1C } \\
\text { Target }\end{array}$ \\
\cline { 2 - 5 } & $\mathrm{mg} / \mathrm{dL}$ & $\mathrm{mmol} / \mathrm{L}$ & $\mathrm{mg} / \mathrm{dL}$ & $\mathrm{mmol} / \mathrm{L}$ & \\
\hline 0-6 years & $100-180$ & $5.6-10.0$ & $110-200$ & $6.1-11.1$ & $<8.5 \%$ \\
6-12 years & $90-180$ & $5.0-10.0$ & $100-180$ & $5.6-10.0$ & $<8 \%$ \\
13-19 years & $90-130$ & $5.0-7.2$ & $90-150$ & $5.0-8.3$ & $<7.5 \%$ \\
\hline
\end{tabular}




\section{Diabetes in Older Adults}

- Diabetes in older adults (more than 65 years) is associated with increased risk of morbidity and mortality.

- An HbA1C goal of 7-8\% is adequate in most elderly and less stringent control is recommended for those with shorter life expectancy.

- Issues that need to be considered in individualizing treatment and setting up glycaemic goals in older adults:

o cognitive dysfunction - difficult for patients to perform complex self-care tasks such as glucose monitoring, changing insulin doses or appropriately maintaining timing and content of diet.

o functional impairment-due to coexisting medical conditions, peripheral neuropathy, and gait and balance problems.

o risk of falls and fractures.

o polypharmacy.

o depression - leading to difficulty with self-care and with implementing healthier lifestyle choices.

o vision and hearing impairment.

\section{Special care in prescribing drugs and insulin:}

- Metformin - low risk of hypoglycaemia but caution in patients with renal impairment or heart failure.
- Thiazolidinediones - fluid retention, exacerbate heart failure and increase the risk of fractures.

- Sulfonylureas - risk of hypoglycaemia, especially with drugs with a long half life (e.g. do not prescribe glibenclamide if $>65$ years of age).

- $\alpha$-glucosidase inhibitors - targets postprandial hyperglycaemia and have a low hypoglycaemic risk, attractive for older patients. However, gastrointestinal intolerance may be limiting its use.

- GLP-1 RA - low risk of hypoglycaemia, but associated nausea and weight loss may cause problems in frail older patients.

- DPP-4 inhibitors - useful for postprandial hyperglycaemia, impart little risk for hypoglycaemia, well tolerated, therefore potential benefits for older patients.

- Insulin therapy - risk of hypoglycaemia should be considered before commencement. Use requires that patients or caregivers have good visual and motor skills and cognitive ability.

- Drugs should be started at the lowest dose and titrated up gradually.

- Polypharmacy may affect compliance, cause drug interactions and worsen adverse effects such as hypoglycaemia and hypotension.

\section{Diabetes in Pregnancy}

\section{Diagnosis of gestational diabetes}

Initial screening at ANC booking: Check 2 hour PPG (after a standard Sri Lankan meal) and if this exceeds $120 \mathrm{mg} / \mathrm{dl}$ proceed to $75 \mathrm{~g}$ OGTT in first trimester to detect previously undiagnosed T2DM.

WHO criteria of 2 hour PPG more than $140 \mathrm{mg} / \mathrm{dl}$ is useful to identify pre-pregnant diabetes.

IADPSG diagnostic criteria for $2 \mathrm{hrs} 75 \mathrm{~g}$ OGTT - if any one value meets or exceeds: Fasting $92 \mathrm{mg} /$ $\mathrm{dl}(5.1 \mathrm{mmol} / \mathrm{L})$, one hour $180 \mathrm{mg} / \mathrm{dl}(10 \mathrm{mmol} / \mathrm{L})$ and $2 \mathrm{hr} 153 \mathrm{mg} / \mathrm{dl}(8.5 \mathrm{mmol} / \mathrm{L})$. This is not validated in South Asian setting.

Tight glycaemic control in the first trimester is crucial to prevent foetal congenital malformations. Therefore preconception planning is of vital importance. 


\section{Pre-pregnancy counselling and workup}

- Achieve the best possible glycaemic control before conception.

- Target $\mathrm{HbA} 1 \mathrm{C}<6.5 \%$

- Women with an elevated $\mathrm{HbA1C}$ value above $8.0 \%$ should be discouraged from becoming pregnant until their control is improved and appropriate contraceptive advice should be provided.

- Initiate insulin to get ideal control.

- Use of metformin should be under specialist care.

- Assess for established diabetes complications before conception.

o Detailed renal and retinal assessment.

- Stop ACE inhibitors, ARBs, statins, fibrates and niacin before conception or as soon as pregnancy is confirmed.

- Alternative antihypertensive agents suitable for use during pregnancy (nifedepine, methyldopa, prazocin, hydralazine, and labetalol) should be substituted.

- Women with diabetes with unplanned or unexpected pregnancy, should be referred to a specialist immediately.

\section{Management of diabetes during pregnancy}

- Encourage self-monitoring of blood glucose levels both fasting and postprandial, preferably $2 \mathrm{hrs}$ after a meal.

Table 3. Targets for capillary blood glucose levels

\begin{tabular}{l|l}
\hline Timing & Target in mg/dl \\
\hline Fasting & $70-90 \mathrm{mg} / \mathrm{dl}$ \\
\hline Pre-meal & $90-100 \mathrm{mg} / \mathrm{dl}$ \\
\hline 1 hr after a meal & $<130 \mathrm{mg} / \mathrm{dl}$ \\
\hline 2 hrs after a meal & $<120 \mathrm{mg} / \mathrm{dl}$ \\
\hline
\end{tabular}

- Women with insulin-treated diabetes should test blood glucose levels at bed time.

\section{Lifestyle management}

Medical nutrition therapy

- All advice should be individualized and should be administered by a nutritionist/dietician/trained health professional.

- Calorie requirements in pregnancy is $30 \mathrm{kcal} / \mathrm{kg} /$ day and in overweight pregnant ladies it is $25 \mathrm{kcal} / \mathrm{kg} /$ day or less.

- Women with pre-existing diabetes who had previous nutritional advice need to be reviewed and revised during pregnancy.

- Dietary advice should be reemphasized at each clinic visit considering the pattern of weight gain.

\section{Exercise}

- A minimum of 30 minutes exercise on most days of the week is recommended during a normal pregnancy (e.g. walking, swimming, cycling and aerobics), unless advised against by a specialist.

\section{Insulin use during pregnancy}

- If lifestyle measures fail to achieve control within one to two weeks start insulin.

- Split mixed or basal bolus regimens are the most suitable.

- Women on insulin should be advised of the risks of hypoglycaemia particularly in the first trimester.

\section{Oral glucose-lowering agents in pregnancy}

- Metformin can be used with caution in pregnancy and breastfeeding.

- All other oral hypoglycaemic agents should be discontinued before pregnancy and insulin substituted.

\section{After delivery}

- Women with pre-existing diabetes before conception:

o Require lower doses of insulin post partum.

o Should be counselled on contraception and preconception care.

- Women with gestational diabetes:

o Could discontinue hypoglycaemic treatment.

o At discharge, reinforce lifestyle modification.

o Screen for persistent diabetes at 6-12 weeks postpartum, using OGTT.

o Rescreen annually.

o Those who have pre diabetes should receive lifestyle intervention or metformin to prevent diabetes. 


\section{Diabetes in Chronic Kidney Disease}

\section{Measurement of glycaemic control}

- HbA1C is affected by the severity of kidney dysfunction and the haematological complications of kidney disease.

- $\mathrm{HbA} 1 \mathrm{C}$ is:

o falsely decreased in haemolysis.

o falsely elevated in acidosis and carbamylation of $\mathrm{Hb}$.

- The "gold standard" is plasma blood glucose (FBG, PPG).

- Treatment decisions can be made by using daily glucose monitoring (SMBG).

\section{Pharmacological treatment}

- Clearance of many drugs and insulin is decreased by kidney disease leading to frequent hypoglycaemic episodes.

- The greatest risk is for patients with moderate to severe CKD (stages 3-5).

\section{Insulin}

- All the available insulin preparations can be used in CKD.

- Insulin types and doses must be individualized for each patient and their level of CKD.

Table 4. Oral agents in CKD

\begin{tabular}{|c|c|c|c|c|}
\hline Class & Drug & $\begin{array}{l}\text { CKD } \\
\text { Stage 3-5 }\end{array}$ & Dialysis & Complication \\
\hline \multirow[t]{5}{*}{ Sulfonylureas } & Tolbutamide & Use with caution & Avoid & Hypoglycaemia \\
\hline & Glibenclamide & Avoid & Avoid & Hypoglycaemia \\
\hline & Glipizide & No dose adjustment & No dose adjustment & \\
\hline & Gliclazide & No dose adjustment & No dose adjustment & \\
\hline & Glimepiride & Low dose: $1 \mathrm{mg} /$ day & Avoid & Hypoglyceamia \\
\hline $\begin{array}{l}\alpha \text {-Glucosidase } \\
\text { inhibitors }\end{array}$ & Acarbose & $\begin{array}{l}\text { Avoid if serum } \\
\text { creatinine }>2 \mathrm{mg} / \mathrm{dl}\end{array}$ & Avoid & $\begin{array}{l}\text { Possible hepati } \\
\text { toxicity }\end{array}$ \\
\hline Biguanide & Metformin & $\begin{array}{l}\text { Caution: } \\
\text { Serum creatinine > } \\
1.6 \mathrm{mg} / \mathrm{dl}\end{array}$ & Avoid & $\begin{array}{l}\text { Lactic acidosis } \\
\text { (extremely } \\
\text { rare) }\end{array}$ \\
\hline TZD & Pioglitazone & No dose adjustment & No dose adjustment & $\begin{array}{l}\text { Fluid retention } \\
\text { Fracture risk }\end{array}$ \\
\hline \multirow[t]{5}{*}{ DPP-4 inhibitors } & Linagliptin & No dose adjustment & No dose adjustment & \\
\hline & Sitagliptin & GFR $30-50 \mathrm{ml} / \mathrm{min}-\downarrow 25 \%$ & $\downarrow 50 \%$ & Hypoglycaemia \\
\hline & & $\mathrm{GFR}<30 \mathrm{ml} / \mathrm{min}-\downarrow 50 \%$ & & \\
\hline & Vildagliptin & $\begin{array}{l}\text { Not recommended if } \\
\text { eGFR }<60 \mathrm{ml} / \mathrm{min}\end{array}$ & & Hypoglycaemia \\
\hline & Saxagliptin & $\begin{array}{l}2.5 \mathrm{mg} / \mathrm{d} \text { if eGFR } \\
<30 \mathrm{ml} / \mathrm{min}\end{array}$ & & Hypoglycaemia \\
\hline \multirow[t]{2}{*}{ GLP-1 RA } & Exenatide & $\begin{array}{l}\text { No dose adjustment } \\
\text { Avoid if GFR }<30\end{array}$ & $\begin{array}{l}\text { No dose adjustment } \\
\text { Avoid if GFR }<30\end{array}$ & \\
\hline & Liraglutide & No dose adjustment & No dose adjustment & \\
\hline
\end{tabular}




\section{Diabetes Management in Hospital Setting}

- All patients admitted to hospital should have their blood glucose tested.

- Hyperglycaemia in the hospital may be due to previously known diabetes, previously undiagnosed diabetes, or hospital-related hyperglycaemia.

- Blood glucose levels persistently higher than $140 \mathrm{mg} /$ $\mathrm{dL}(7.8 \mathrm{mmol} / \mathrm{L})$ should be considered for treatment in hospitalized patients.

- HbA1C values $>6.5 \%$ suggests undiagnosed diabetes that preceded hospitalization.

\section{Non-critically ill patients}

- Individualized care under a specialist is recommended.

- In most ill patients basal bolus or multiple doses of split-mixed insulin regimen is appropriate.

o Total daily dose of insulin:

- 0.5-0.7 units/kg for type 1 diabetes and

- 0.4-1.0 units $/ \mathrm{kg}$ or more for patients having type 2 diabetes.

o Use $50 \%$ of the calculated daily dose as basal insulin (divided in two doses if isophane insulin is used) and rest as pre-meal bolus in divided doses.

o If the pre-meal glucose is "high", extra dose of bolus insulin can be given (correction-dose of insulin).

o Traditional sliding scale insulin regimens are no longer recommended and when used as sole therapy, result in large swings in blood glucose levels.

- Hypoglycaemia should be avoided and treatment regimen should be modified when blood glucose values are $<70 \mathrm{mg} / \mathrm{dL}(3.9 \mathrm{mmol} / \mathrm{L})$.

Table 5. Blood glucose targets in hospitalized patients

\begin{tabular}{ll}
\hline Pre-meal & $<140 \mathrm{mg} / \mathrm{dL}(7.8 \mathrm{mmol} / \mathrm{L})$ \\
\hline RBS & $<180 \mathrm{mg} / \mathrm{dL}(10 \mathrm{mmol} / \mathrm{L})$ \\
\hline
\end{tabular}

\section{Critically ill patients}

- In critically ill ICU patients, insulin infusion should be started if blood glucose levels are $>180 \mathrm{mg} / \mathrm{dL}$ (see Appendix 2).

- Blood glucose level should be maintained between 140 and $180 \mathrm{mg} / \mathrm{dL}(7.8-10.0 \mathrm{mmol} / \mathrm{L})$ while the lower limit is preferred.

- In selected patients lower blood glucose target $(<140$ $\mathrm{mg} / \mathrm{dL}$ ) may be appropriate. However, targets less than $110 \mathrm{mg} / \mathrm{dL}$ (6.1 mmol/L) are not recommended.

- Transition from I.V. insulin infusion to subcutaneous insulin:

o Calculate total daily dose used in infusion and give it as basal bolus regimen.

o Continue infusion for 1-2 hours after the first subcutaneous dose.

\section{Diabetes management in surgical patients}

- Elective surgery should be postponed whenever possible if glycaemic control is poor ( $\mathrm{HbAlC} \geq 9 \%$ ).

- Blood glucose should be maintained between 90-180 $\mathrm{mg} / \mathrm{dl}$ during the peri-operative period.

- Patients undergoing prolonged major surgery should be commenced on an insulin infusion, prior to induction of anaesthesia with hourly blood glucose measurements and continued for 24 hours postoperatively or until the patient starts eating adequately. Special attention to the potassium level is recommended.

- For all other surgical procedures in diabetic patients, the following practice is acceptable:

o Maintain usual meal plan, insulin or oral glucose lowering medications on day and evening prior to surgery.

o In the morning of surgery, $50 \%$ of the usual dose of basal insulin requirement can be given.

o During this time short/rapid acting insulin or oral glucose lowering drugs should not be given (unless as a correction dose).

o Check blood glucose every 2 hours before and during surgery.

- "Sliding scale insulin" is NOT recommended for the post-operative management of diabetes when used as sole therapy. 


\section{References}

1. Shaw JE, Sicree RA, Zimmet PZ. Global estimates of the prevalence of diabetes for 2010 and 2030. Diabetes Research and Clinical Practice 2010; 87: 4-14.

2. Katulanda P, Constantine GR, Mahesh JG, et al. Prevalence and projections of diabetes and pre-diabetes in adults in Sri Lanka - Sri Lanka Diabetes, Cardiovascular Study. Diabet Med 2008: 25(3): 1062-69.

3. UK Prospective Diabetes Study (UKPDS) Group. Intensive blood-glucose control compared with conventional treatment and risk of complications in patients with type 2 diabetes. Lancet 1998; 352: 837-65.

4. Holman RR, et al. 10-year follow-up of intensive glucose control in type 2 diabetes. N Engl J Med 2008; 359: 1577-89.

5. Gaede $P$, Vedel $P$, Larsen N, et al. Multifactorial intervention and cardiovascular disease in patients with type 2 diabetes. N Engl J Med 2003; 348(5): 383-93.

6. Position Statement Writing Group. Management of hyperglycaemia in type 2 diabetes: a patient-centred approach. Position Statement of the American Diabetes Association (ADA) and the European Association for the Study of Diabetes (EASD). Diabetes Care 2012; 35(6): 1364-79.
7. American Diabetes Association. Standards of medical care in diabetes 2012. Diabetes Care 2012; 35 (Suppl 1): S11-S63.

8. De Silva S, Premarathne P, Jayasena A. Diabetes and Your Child. 1st ed. Colombo: Triple Publicity; 2011.

9. National Kidney Foundation: KDOQI clinical practice guidelines and clinical practice recommendations for diabetes and chronic kidney disease. Am J Kidney Dis 2007; 49: s1-s180.

10. IDF Clinical Guidelines Task Force. Global Guideline on Pregnancy and Diabetes. Brussels: International Diabetes Federation, 2009.

11. Clement $\mathrm{S}$ et al. American Diabetes Association - Diabetes in Hospitals Writing Committee. Management of diabetes and hyperglycaemia in hospitals. Diabetes Care 2004; 27(2): $553-91$.

12. Joslin Diabetes Centre and Joslin Clinic guideline for inpatient management of surgical and ICU patients with diabetes, 2009.

13. Spellman CW, Triplitt C, Wyne KL, Greene S. IV Insulin Infusion Protocol for Critically Ill Adult Patients in the ICU Setting. www.tdctoolkit.org/algorithms_and_guidelines.asp

14. Diabetes in Pregnancy Study Group India Working Committee. Diagnosis and Management of GDM. Diabetology 2013. In print.

\section{Definitions}

HbA1C: The predominant form of glycated haemoglobin, present in red blood cells, and formed when the normal haemoglobin A reacts non-enzymatically with glucose. As the reaction is slow and only concentration dependent, the amount of $\mathrm{HbA} 1 \mathrm{C}$ formed is proportional only to the concentration of $\mathrm{HbA}$ and glucose. As $\mathrm{HbA}$ remains in the circulation for around 3 months, the amount of $\mathrm{HbAlC}$ present, expressed as a percentage of $\mathrm{HbA}$, is proportional to the glucose concentration over that time.

Aerobic exercise: Constant moderate intensity work that uses up oxygen at a rate in which the cardio respiratory system can replenish oxygen in the working muscles.

Resistance training: Resistance training works to increase muscle strength and endurance by doing repetitive exercises with weights, weight machines, or resistance bands.

$\alpha$-Glucosidase inhibitors: Group of drugs which inhibit the digestion of complex carbohydrates in the gut, and thus flatten the post-meal blood glucose excursion.

Thiazolidinediones: A group of drugs which improve insulin sensitivity in people with reduced sensitivity to their own or injected insulin; presently the licensed drugs are both of the chemical group known trivially as 'glitazones' or PPAR- $\gamma$ agonists.
DPP-4 inhibitors: This class of drugs lower blood glucose levels by blocking an enzyme known as dipeptidyl peptidase IV (DPP-4), which is responsible for breaking down glucagon-like peptide-1 that stimulate the beta cells and slows gastric emptying time after a meal. If DPP-4 is inhibited, then glucagon-like peptide- 1 can stimulate the release of insulin for a longer period of time, thereby lowering the glucose level in the blood and slowing the rate of absorption of food. DPP-4 inhibitors are prescribed for type 2 diabetes only.

GLP-1 RA: GLP-1 is an incretin hormone and by definition stimulates the release of insulin from pancreatic beta cells in conjunction with carbohydrates that are absorbed from the gut. GLP-1 agonist are drugs that function as an agonist for the GLP-1 receptor. This will stimulate the beta cells to secrete more insulin in response to food in the stomach.

Insulin analogues: A derivative of human insulin in which change of the amino-acid sequence alters duration of action after injection.

Insulin regimen: A therapeutic combination of different insulin preparations, including time of injection and frequency during a day. 


\section{Annexure 1}

\section{Sample meal plans for patients with diabetes}

Ideally a meal plan should be individualized based on age, height, weight and physical activity level of the patient. In the plans below, 1 cup is a tea-cup $(125 \mathrm{ml})$.

\section{Meal plan - 1 (1800 kcal) \\ For weight maintenance in most}

\section{Breakfast}

Non-fat milk 1 cup (morning tea)

Rice 2 cups

Non-starchy vegetables 3 cups

Fish/meat $1-2$ pieces

$$
\text { Or }
$$

Green gram/chick peas 2 cups with "Lunu miris"

\section{Morning snack}

Fruits 1 cup (e.g. 1 small banana)

\section{Lunch}

Rice 2 cups

Non-starchy vegetables 3 cups

Fish/meat 1-2 pieces

\section{Afternoon snack}

Non-fat milk 1 cup

Fruits 1 cup or 2 sugar-free biscuits

\section{Dinner}

Red string hoppers - 5-7

Non-starchy vegetables 2 cups

Dhal $1 / 2$ cup

$$
\text { Or }
$$

Rice 2 cups

Non-starchy vegetables 2 cups

Fish / Meat 1-2 pieces

\section{Late night snack}

Non-fat milk 2 cups or

2 sugar-free biscuits or fruits 1 cup

\section{Meal plan - 2 (1300 kcal) \\ For weight loss in most}

\section{Breakfast}

Non-fat milk 1 cup (morning tea)

Rice 1 cup

Non-starchy vegetables 3 cups*

Fish/meat 1 piece

$$
\text { Or }
$$

Green gram/chick peas 1 cup with "Lunu miris"

Morning snack

Fruits 1 cup (e.g. 1 small banana)

\section{Lunch}

Rice 1 cup

Non-starchy vegetables 3 cups*

Fish/meat 1 piece

\section{Afternoon snack}

Non-fat milk 1 cup

Fruits 1 cup or 2 sugar-free biscuits

\section{Dinner}

Red string hoppers - 3-5

Non-starchy vegetables 2 cups*

Dhal $1 \frac{1}{2}$ cup

$$
\text { Or }
$$

Rice 1 cup

Non-starchy vegetables 2 cups*

Fish/meat 1 piece

\section{Late night snack}

Non-fat milk 1 cup or

2 sugar-free biscuits

*Vegetables should be cooked without coconut milk 


\section{Annexure 2}

\section{I.V. Insulin protocol for ICU patients}

\begin{tabular}{|c|c|c|c|c|c|c|c|}
\hline \multirow{2}{*}{\multicolumn{2}{|c|}{$\begin{array}{c}\text { Algorithm } 1 \\
\text { Glucose units/h }\end{array}$}} & \multicolumn{2}{|c|}{ Algorithm 2} & \multicolumn{2}{|c|}{ Algorithm 3} & \multicolumn{2}{|c|}{ Algorithm 4} \\
\hline & & Glucose & units/h & Glucose & nits/h & Glucose & units/h \\
\hline$<70$ & Off & $<70$ & Off & $<70$ & Off & $<70$ & Off \\
\hline $70-109$ & 0.2 & $70-109$ & 0.5 & $70-109$ & 1 & 70-109 & 1.5 \\
\hline $110-119$ & 0.5 & $110-119$ & 1 & $110-119$ & 2 & $110-119$ & 3 \\
\hline $120-149$ & 1 & $120-149$ & 1.5 & $120-149$ & 3 & $120-149$ & 5 \\
\hline $150-179$ & 1.5 & $150-179$ & 2 & $150-179$ & 4 & $150-179$ & 7 \\
\hline $180-209$ & 2 & $180-209$ & 3 & $180-209$ & 5 & $180-209$ & 9 \\
\hline $210-239$ & 2 & $210-239$ & 4 & $210-239$ & 6 & $210-239$ & 12 \\
\hline $240-269$ & 3 & $240-269$ & 5 & $240-269$ & 8 & $240-269$ & 16 \\
\hline $270-299$ & 3 & $270-299$ & 6 & $270-299$ & 10 & $270-299$ & 20 \\
\hline $300-329$ & 4 & $300-329$ & 7 & $300-329$ & 12 & $300-329$ & 24 \\
\hline $330-359$ & 4 & $330-359$ & 8 & $330-359$ & 14 & $330-359$ & 28 \\
\hline$>360$ & 6 & $>360$ & 12 & $>360$ & 16 & $>360$ & 32 \\
\hline
\end{tabular}

- Intravenous fluids: Most patients will need 5-10 g of glucose/hour (5\% dextrose or dextrose saline at 100-200 ml/hour or equivalent).

- Adjusting the infusion:

o Algorithm 1: Start here for most patients.

o Algorithm 2: Start here if receiving glucocorticoids, previously on high TDD of insulin etc.

- Moving algorithms:

o Moving up: When glucose remains outside the target range after titrating insulin.

o Moving down: When glucose is $<110 \mathrm{mg} / \mathrm{dL} \times 2$ or decreases $>60 \mathrm{mg} / \mathrm{dl}$ in 1 hour.

- Patient monitoring: Do hourly capillary glucose until glucose is within goal and may extend to 2-4 hourly if stable.

This algorithm is not intended to be used for those individuals with type 1 diabetes, diabetic ketoacidosis or hyperglycaemic hyperosmolar states. 